\title{
O saber-pesquisar sob o olhar de quem está entrando na Pós-Graduação em Educação ${ }^{1}$
}

\section{Knowledge about researching under the freshmen Education Graduate students' point of view}

\author{
Messias Dieb ${ }^{2}$
}

\begin{abstract}
RESUMO
No presente artigo discuto a relação do pesquisador iniciante com a atividade de pesquisa no campo educacional, a partir das ideias de Charlot (2000) sobre as relações do sujeito com o mundo, com os outros e consigo mesmo na construção de si e de seus saberes. Na constituição dos dados, 30 mestrandos do Programa de Pós-Graduação em Educação, da Universidade Federal do Ceará e da Universidade Estadual do Ceará, escreveram um balanço de seus saberes sobre o que é pesquisar. Para eles, a pesquisa é uma ação formativa que visa à solução de problemas da realidade social e de questões que afligem diretamente o professor. Finalizo, refletindo sobre alguns desafios na trajetória de pesquisa desses estudantes, os quais consideram a atividade como um elemento importante para o seu desenvolvimento profissional.
\end{abstract}

Palavras-chave: pesquisa educacional; relação com o saber; desenvolvimento profissional.

\section{DOI: $10.1590 / 0104-4060.44078$}

1 Trabalho originalmente apresentado como comunicação oral no II Encontro Luso-Brasileiro sobre Trabalho Docente e Formação, na Faculdade de Psicologia e de Ciências da Educação da Universidade do Porto - Portugal. Faz parte do projeto de pesquisa "O pesquisador iniciante na área de Educação e sua relação com o saber pesquisar". Agradeço à estudante Pollyana Nobre Melo, bolsista da Fundação Cearense de Apoio à Pesquisa (FUNCAP), no Programa Institucional de Bolsas de Iniciação Científica (PIBIC), pelo cuidadoso trabalho de coleta e sistematização dos dados durante o desenvolvimento desta pesquisa.

2 Universidade Federal do Ceará. Faculdade de Educação. Fortaleza, Ceará, Brasil. Rua Waldery Uchoa, nº 01 - Bairro Benfica. CEP: 60020-110. E-mail: mhdieb@gmail.com 


\begin{abstract}
In this paper, I reflect on the relationships of freshman graduate students with the research activity in the education field based on Charlot's propositions (2000) about relationships of the individuals with the world, the others and themselves to self-building and the construction of their own knowledge. A written balance of knowledge developed by 30 Education students attending Masters Degree from the Federal University of Ceara and from the State University of Ceara, in Brazil, composed the data in which they define researching, and they explain what it means to them. In their point of view research is a formative action that intends to solve the social reality problems, and to find answers to the questions that disturb the teachers' practice. In the end, I expose some challenges faced by the students, who consider research an important constituent of their professional development.
\end{abstract}

Keywords: educational research; knowledge relations; professional development.

\title{
Introdução
}

Há algum tempo venho refletindo sobre a atividade de pesquisa na área das Ciências Humanas e o modo como o pesquisador tem se relacionado com esse saber-fazer. (DIEB, 2007). Não obstante tal empreendimento acadêmico, minhas indagações acerca do tema ainda não foram satisfatoriamente respondidas, especialmente no que concerne à pesquisa no campo da Educação. Por isso, iniciei novo estudo no qual utilizei uma técnica de pesquisa chamada balanço do saber (bilan du savoir), com a cooperação de 30 (trinta) mestrandos recém-ingressos no Programa de Pós-Graduação em Educação Brasileira, da Universidade Federal do Ceará (UFC), e no Programa de Pós-Graduação em Educação, da Universidade Estadual do Ceará (UECE). Esses dois programas foram escolhidos por serem atualmente os dois únicos programas de Pós-Graduação stricto sensu nessa área no Estado do Ceará, assim como pelo fato de que as duas instituições são igualmente reconhecidas como sendo as duas maiores universidades públicas desse estado.

A técnica utilizada foi elaborada por uma equipe de pesquisa francesa denominada ESCOL (Éducation, Socialisation et Collectivités Locales), da qual Charlot (2000) foi o idealizador, e consiste em uma produção de texto, a partir de um enunciado que busca estimular os sujeitos a avaliarem por escrito os processos e os produtos de sua aprendizagem, o que pode nos permitir uma 
inferência sobre os sentidos que eles atribuem ao que aprendem. Por meio do balanço do saber, é possível instigar os participantes de uma determinada pesquisa a realizarem aferições acerca dos processos relativos à aprendizagem de um determinado saber ou à apropriação de uma dada atividade. A natureza desse instrumento gerador de dados incide, pois, na elaboração de um texto escrito de próprio punho pelos colaboradores da pesquisa, a partir de um gatilho inicial, ou seja, de um comando que deve ser cuidadosamente preparado pelo pesquisador a fim de impetrar dados relacionados ao objeto de sua pesquisa. Em nosso caso, o gatilho foi o seguinte enunciado:

Desde que comecei a estudar, tenho aprendido muitas coisas sobre pesquisa: na escola, nos livros, com os colegas e os professores, e agora na Universidade. Quais foram as coisas mais importantes que aprendi sobre a pesquisa? O que eu sei sobre um projeto de pesquisa? Que coisas eu aprendi sobre a construção de um objeto de estudo? Baseado em quê, eu posso afirmar que meu trabalho é uma pesquisa em Educação? Por que eu posso dizer que sou um pesquisador em Educação? Onde mesmo aprendi essas coisas? Quem me as ensinou?

A aplicação da técnica supracitada foi antecedida por convites para conversas informais com vários mestrandos recém-ingressos nos dois Programas de Pós-Graduação em Educação acima referidos. Inicialmente, consegui conversar informalmente e convidar 40 mestrandos, contudo, após esses contatos iniciais, apenas 30 estudantes tiveram a disponibilidade de tempo para serem informantes da pesquisa. Através de um termo de consentimento esclarecido, no qual foram estabelecidos os acordos éticos ${ }^{3}$ de que suas identidades seriam preservadas, os estudantes concordaram por escrito em participar da pesquisa e, assim, foram agendados encontros individualizados ao longo do primeiro semestre letivo do ano de 2013. Foi nesse contexto, portanto, que pude ter acesso aos dados que emergiram do balanço do saber, produzidos por aqueles pesquisadores em estágio inicial de formação acadêmica na área de Educação, e que aqui serviram de base para uma reflexão acerca da atividade de pesquisa.

Os referidos mestrandos são aqui considerados sujeitos iniciantes na atividade de pesquisa no campo educacional devido ao fato de que, mesmo tendo passado por alguma experiência de iniciação científica ou de Pós-Graduação lato

3 Por razões éticas, os nomes que utilizarei mais adiante para me referir aos mestrandos são fictícios. 
sensu, alguns deles adentram a Pós-Graduação stricto sensu em Educação, no nível de mestrado, apresentando ainda muitas dúvidas, incertezas e inseguranças acerca dessa atividade. Minha suposição de trabalho, a qual serviu de base para analisar os textos produzidos, foi a de que uma dessas dúvidas, ou inseguranças, está relacionada mais especificamente à compreensão do que significa um objeto de estudo no campo da Educação e de como este pode ou deve ser abordado, uma vez que as exigências feitas na Pós-Graduação stricto sensu para planejar uma pesquisa e relatá-la em uma dissertação de mestrado são bem mais severas do que aquelas voltadas para a escrita de um relatório PIBIC $^{4}$ e/ou uma monografia de conclusão de curso. Considerando, pois, a conjuntura descrita acima, neste texto, reflito sobre a temática do "fazer pesquisa" a partir da seguinte questão: De que maneira o pesquisador iniciante compreende e descreve os processos relacionados a uma "Pesquisa em Educação"?

O objetivo do estudo foi o de analisar a relação do pesquisador iniciante com a atividade de pesquisa no campo da Educação, por meio da compreensão que ele apresenta acerca do processo de construção do conhecimento nessa área. A análise e a reflexão sobre essa questão ocorreram basicamente focando trechos dos balanços de saber em que os sujeitos expressavam tal compreensão. Porém, apenas alguns desses trechos foram selecionados para apresentação, neste texto, devido ao curto espaço do qual poderia dispor e que não me permitiria apresentar um volume maior de dados. Assim, é relevante informar que as afirmações transcritas e as atribuídas aos mestrandos foram selecionadas, dentro do conjunto dos 30 balanços, por serem as mais representativas das ideias recorrentes no conjunto dos textos analisados.

Nesse percurso, foram basilares alguns postulados teóricos inerentes à sociologia do sujeito, especificamente, a abordagem da relação com o saber, proposta por Charlot (2000), os quais foram articulados ao longo do texto, naquilo que os aproximam, com algumas ideias de Bourdieu $(1996,1998)$ e Guareschi (2001) sobre o modo de os sujeitos se constituírem a partir das relações que estabelecem com mundo, com os outros e consigo mesmo. Assim sendo, sistematizarei a escrita da presente reflexão com base na compreensão que os pesquisadores iniciantes apresentam, em seus balanços de saber, sobre o fazer da atividade de pesquisa para, em seguida, discutir sobre algumas dificuldades

4 No Brasil, "O Programa Institucional de Bolsas de Iniciação Científica (PIBIC) visa apoiar a política de Iniciação Científica desenvolvida nas Instituições de Ensino e/ou Pesquisa, por meio da concessão de bolsas de Iniciação Científica (IC) a estudantes de graduação integrados na pesquisa científica. A cota de bolsas de (IC) é concedida diretamente às instituições, estas são responsáveis pela seleção dos projetos dos pesquisadores orientadores interessados em participar do Programa. Os estudantes tornam-se bolsistas a partir da indicação dos orientadores". Para outras informações, consulte-se o site <http://www.cnpq.br/web/guest/pibic>. Acesso em: 22 nov. 2015. 
que eles podem enfrentar a partir dessa compreensão de pesquisa, especialmente no complexo campo da Educação.

\section{$O$ fazer da pesquisa para os mestrandos: saberes e sentidos}

Não obstante as propriedades psíquicas envolvidas em qualquer tipo de aprendizagem, os elementos que gravitam em torno das situações relacionais (sociais) em que se encontram os indivíduos também operam muito fortemente no contexto da construção do conhecimento e da construção de si, ou seja, fornecem substratos necessários à formação da subjetividade desses indivíduos. Sendo assim, um aluno de mestrado, por exemplo, recém-ingresso em uma nova comunidade de discursos e práticas, que é a comunidade da Pós-Graduação stricto sensu, tende a se dar conta de que precisa apreender e/ou aperfeiçoar uma outra maneira de pensar, diferentemente dos modos espontâneos de compreender o mundo e seus objetos na cotidianidade. Isto implica, por conseguinte, uma necessidade de "sobrevivência" para o sujeito que acaba de adentrar o universo da pesquisa e a comunidade dos pesquisadores.

Com efeito, podemos afirmar que a raiz dessa necessidade do sujeito fixa residência na própria ação de sua aprendizagem que, conforme nos explica Bruner (1966, p. 113), traduz uma necessidade que "está tão integrada no homem que é quase involuntária". Em outras palavras, isto quer dizer que, inevitavelmente, a cada entrada do sujeito em um universo novo de conhecimentos e de saberes, como o da pesquisa, por exemplo, ele é impelido a construir uma nova relação com o saber (CHARLOT, 2000), ou seja, é impelido a apreender e a construir novas maneiras de ser e de estar nesse novo mundo/espaço/tempo que o acolhe. Nessa direção, os mestrandos vão paulatinamente construindo suas ideias e representações acerca da atividade científica, a partir do contato com os sujeitos mais experientes e, especialmente, dos desafios que lhes são lançados no dia a dia do curso.

Nessa trajetória, o estudante normalmente precisa dar conta de uma agenda de compromissos com os quais ele nem de longe imaginava lidar, especialmente aquele que não passou pela experiência da iniciação científica e da Pós-Graduação lato sensu. Dentre esses compromissos, merecem destaque: as atividades ligadas a um determinado grupo de pesquisa, a pressão para produzir e publicar seus textos, as leituras em língua estrangeira, os prazos curtos e muitas vezes inegociáveis, destinados a etapas fulcrais do curso de Pós-Graduação, tais como as qualificações e a defesa da dissertação, além, é claro, das oscilações 
de humor de seu(sua) orientador(a) e demais professores. Concomitantemente a esses compromissos, e em função deles, o pós-graduando precisa centrar sua atenção no fazer de uma pesquisa que vai lhe outorgar o título acadêmico de mestre em Educação. Nesse espaço/tempo de relações humanas, o mestrando vai, portanto, deparando-se com uma linguagem e com uma série de práticas que são próprias à comunidade científica e que ajudam a configurar historicamente o discurso acadêmico.

É exatamente esse discurso que atuará na aprendizagem do saber-fazer da pesquisa e que guiará, até certo ponto, o aprendiz pelos novos caminhos da vida acadêmica. Isto não significa dizer, entretanto, que o pesquisador iniciante no mestrado será um mero produto desse discurso ou dessa nova posição social que ele passou a ocupar. A apropriação da atividade científica, assim como a de qualquer outra atividade genuinamente humana, não transcorre sem que haja confrontos e disputas de subjetividades.

Não obstante essa constatação, a atividade científica, segundo Bourdieu (1996, p. 88), “[...] engendra-se na relação entre disposições reguladas de um habitus científico que é, em parte, produto da incorporação da necessidade imanente do campo científico e das limitações estruturais exercidas por esse campo em um momento dado do tempo". Com base nesses aspectos, posso alegar que, em suas descobertas acerca de como realizar uma pesquisa, o mestrando terá muito de suas representações em torno dessa atividade fomentadas pela força do citado habitus. Todavia, como bem afirma Charlot (2000, p. 33), o sujeito é um ser social na mesma proporcionalidade de que é um ser singular e, por isso, "[...] interpreta o mundo, dá um sentido a esse mundo, à posição que ocupa nele" e obviamente às atividades que realiza nos espaços da atividade humana.

Nessa direção, ainda de acordo com Charlot (2000, p. 72), é importante salientar que toda relação com o saber apresenta uma dimensão epistêmica, ao mesmo tempo em que comporta também uma dimensão de identidade e que não deixa de ser uma relação social, apesar de ser a relação de um sujeito. Segundo o mesmo autor, "[...] essa dimensão social não se acrescenta às dimensões epistêmica e identitária: ela contribui [significativamente] para dar-lhes uma forma particular". (CHARLOT, 2000, p. 73). Portanto, quando um estudante inicia sua trajetória no universo da Pós-Graduação stricto sensu, ele se vê impelido a estabelecer o mais rápido possível uma relação epistêmica com o saber pesquisar, isto é, ele terá que construir uma definição para si do que é a atividade de pesquisa.

Hoje ao pensar em pesquisa, aponto dois aspectos: primeiro, a função deste trabalho e sua contribuição para a sociedade; em segundo lugar, 
os procedimentos, de cunho mais técnico relacionados à pesquisa. Assim entendo a pesquisa: como uma série de procedimentos visando solucionar um problema, responder uma questão. (Maurício/UECE).

A pesquisa é um conhecimento que eu vou construir, que eu vou produzir, espero contribuir para a melhoria da qualidade da Educação. Proporcionar mais elementos à Educação [...]. Então, eu acho que esse trabalho deve trazer essa contribuição para melhorar a qualidade, a partir do momento que traz, por exemplo, uma reflexão minha sobre a gestão na Educação Infantil. (Mariana/UFC).

Como podemos perceber, a ideia de pesquisa para os mestrandos que participaram do estudo, representados aqui por Maurício e Mariana, é a de que se trata de uma atividade de grande relevância para o meio social onde eles se situam, bem como é caracterizada por um forte aspecto técnico, sem o qual parecem tornar-se inalcançáveis os objetivos visados por essa atividade. Nesse mesmo movimento, os mestrandos elucidam indiretamente a dimensão identitária que acompanha essa relação epistêmica e seus matizes igualmente sociais, visto que eles são inerentes uns aos outros.

Dito de outro modo, Maurício e Mariana, ao exporem sua compreensão conceitual sobre a pesquisa, delineiam também os contornos identitários de um pesquisador, pelos quais, certamente, eles desejam ser reconhecidos. Em primeiro lugar, o pesquisador em Educação é alguém cujo trabalho precisa dar uma contribuição para a sociedade e, em segundo, seu saber-fazer, como uma atividade de pesquisa, necessita estar associado a um conjunto de procedimentos técnicos e teóricos que validarão os resultados e, consequentemente, o status de pesquisador. Para se posicionar deste modo, os sujeitos estão provavelmente baseados nos preceitos orientadores do habitus científico, de que nos fala Bourdieu, mas também nas suas próprias maneiras de assimilação desse saber-fazer.

Após esse processo epistêmico de objetivação-denominação (CHARLOT, 2000) sobre a pesquisa para si mesmos, como uma série de procedimentos a serem seguidos e que visam a dar uma contribuição social, os sujeitos empreendem a construção dos artefatos metodológicos a serem seguidos para se apropriarem do objeto que estudam. O referido processo revela um movimento que, ao mesmo tempo, constitui um saber-objetivado e um sujeito consciente de sua apropriação acerca desse saber, o qual se apresenta como um mundo distinto do mundo das ações humanas. Nesse processo, como afirma Charlot, a aprendizagem consiste na capacidade de externar, por meio da linguagem, "conteúdos 
de pensamento" que se configuram como um produto elaborado a partir do ato de aprender, sendo tais conteúdos o que podemos designar de saberes. No caso em análise, os sujeitos externaram seus saberes sobre a pesquisa, os quais foram construídos ao longo de sua trajetória de formação e, principalmente, de atuação profissional na área.

No entanto, no processo de apropriação da atividade de pesquisa, é preciso haver um movimento que leve os sujeitos a passarem do estágio de um "saber sobre a pesquisa" para aquele do "saber pesquisar" efetivamente. É nesse momento que os pesquisadores iniciantes passam a se dar conta, com mais clareza, dessa "espécie de sentido do jogo científico", como diria Bourdieu (1998, p. 23), no qual deverão articular "o que" precisa ser feito com o "como" deve ser feito e o "para que" deve ser feito.

A partir de leituras sobre o ato de pesquisar [...] posso afirmar que as coisas mais importantes que aprendi sobre pesquisa foi o "envolvimento" que se pode ter com o universo a ser pesquisado. É lógico que aqui não me refiro unicamente ao contato com o campo da pesquisa em si, mas à inspiração inicial que se tem para buscar respostas e também toda a fundamentação teórica que possa embasar tais caminhos na busca por respostas. [...] Aprendi que o contato com o universo real [...] é que funciona como um impulso, um estímulo que aciona no pesquisador [...] inquietação para querer melhor entender os problemas desse universo real. (Amanda/UFC).

As tuas perguntas vão gerando os teus objetivos. Os teus objetivos vão gerar um, vamos dizer assim, campo de exploração para que você possa entender o melhor modo de como responder aquelas perguntas iniciais [...] e, para responder essas perguntas, você precisa formalizar as coisas. (Jorge /UECE).

Como se pode notar, Amanda e Jorge apresentam uma compreensão interessante de como o grupo dos pesquisadores iniciantes pode construir mais adequadamente seu objeto de estudo. Para eles, é por meio do envolvimento com o universo a ser pesquisado que o pesquisador pode tomar, mais "fácil e seguramente", suas decisões quanto ao que pretende e como pretende abordar esse universo. Nesse sentido, por "universo a ser pesquisado", os estudantes parecem compreender como sendo não apenas os espaços físicos ligados aos 
temas de seu interesse, mas também ao conjunto dos significados construídos e partilhados pelas pessoas que ocupam e configuram esses espaços.

Ao ler esses comentários, comecei a pensar sobre o fato de que, na condição de orientadores de suas dissertações, é importante que nós, professores em programas de Pós-Graduação, saibamos o que os estudantes já têm solidificado em termos de compreensão sobre o saber-pesquisar. Isso se justifica porque, na relação orientador-orientando, iremos nos deparar com o jogo de poder que implica simbolicamente aquele "que já sabe" e está ensinando aquele que está aprendendo. No entanto, quem está aprendendo também já sabe de muitas coisas e, provavelmente, apreendeu o que sabe de um modo muito singular, ou seja, particularizado em sua essência como sujeito que se afirma no mundo.

É preciso mostrar que você tem um conhecimento adequado para realizar aquela pesquisa, ou pelo menos anunciar: - Eu não estou começando do zero, eu tenho uma bagagem. Digo adequado no sentido que a academia pede, entendeu? Tanto é que uma das coisas que mais me deixou triste foi que na seleção, é [...] o meu projeto foi entregue no momento da seleção e quando fui estudar para a prova, eu tive contato com um autor e me apaixonei profundamente por ele, é perfeito. (Fernanda/UFC).

De acordo com as ideias de Guareschi (2001, p. 56), "[...] sem perder sua singularidade, pois continua sempre sendo um ser único e irrepetível, [a] subjetividade [do indivíduo singular] é composta das milhões de relações que ele estabelece durante toda sua existência". Assim sendo, a relação orientador-orientando será uma a mais, entre essas milhões, na qual tanto a subjetividade do primeiro como a do segundo estará permanentemente em atrito e, consequentemente, se (re)constituindo. Posso depreender, principalmente das falas de Amanda, acima, e de Antônio, abaixo, que é no encontro com o seu outro, na relação com esse outro, que o pesquisador, ainda que iniciante, afirma-se como tal.

Você deve ter uma certa credibilidade naquilo que faz. Você não pode fazer algo só porque um orientador quer, só porque a sociedade tá impondo aquilo como tema da moda. Você deve fazer aquilo com uma certa finalidade. Finalidade que está envolvida com você, com a comunidade e com a Universidade também. (Antônio/UFC). 
Assim, se todo sujeito se constitui a partir de sua relação com o saber, enquanto relação com o mundo, com o outro e consigo mesmo, como sugere Charlot (2000), então, é por meio do encontro entre o pesquisador e o universo dos outros sujeitos, seja no curso em si ou no espaço da pesquisa, que ele vai ajustar seu foco de interesse, assim como vai conseguir perceber o modo como poderia acessar mais adequadamente o universo dos pesquisados, o qual se the apresenta como realidade a ser indagada. Para pensar um pouco mais sobre isso, fui ao encontro das ideias de Amorim (2001), que, sob uma perspectiva altamente dialógica, reflete acerca do conjunto das relações que o pesquisador constrói com o fenômeno a ser estudado, com os sujeitos de sua pesquisa e, por extensão, constrói consigo mesmo.

O conjunto dessas relações é permeado pela questão da ética na pesquisa, posto que o pesquisador, quando assume a interação como a principal característica do estudo em torno dos fenômenos humanos, deve entender que

[...] a produção de conhecimentos e o texto em que se dá esse conhecimento são uma arena onde se confrontam múltiplos discursos. Por exemplo, entre o discurso do sujeito a ser analisado e conhecido e o discurso do próprio pesquisador que pretende analisar e conhecer, uma vasta gama de significados conflituais e mesmo paradoxais vai emergir. Assumir esse caráter conflitual e problemático da pesquisa em Ciências Humanas [onde se situa a Educação] implica renunciar a toda ilusão de transparência: tanto do discurso do outro quanto do seu próprio discurso. (AMORIM, 2001, p. 12).

Essas ideias da autora, citada acima, parecem ganhar maior concretude quando pensamos no próprio conceito de relação, o qual, segundo nos apresenta Guareschi (2002, p. 151), “[...] é uma realidade que para poder ser necessita de outra, senão não é". Assim, ao enveredarmos por essa via de pensamento, torna-se quase impossível não despertar o interesse de pensar sobre o encontro, acima referido, entre o pesquisador iniciante e os outros sujeitos selecionados como possíveis colaboradores de sua pesquisa. E isso é o que tento fazer neste momento.

A relevância desse fato se justifica na medida em que implica, igual e concretamente, a necessidade, tantas vezes despercebida, de os mestrandos se questionarem sobre os seus próprios interesses quanto à investigação iniciada, ou seja, sobre seus móbeis e relações com aquilo que estão se propondo a estudar. Em outros termos, trata-se da necessidade de elucidarem a dimensão identitária de sua própria relação com o saber enquanto relação consigo mesmo. Afinal, a 
pesquisa é a tessitura de um texto em um contexto cujo perfil plural e conflituoso não se distancia de nenhum outro trabalho que envolve relações intersubjetivas, como veremos na sequência dessa reflexão.

\section{O pesquisador iniciante em Educação e seu outro no campo de pesquisa}

De acordo com Gatti (2002, p. 62), a Educação é uma área de conhecimento e uma área profissional que se utiliza das ideias e do saber acumulado em outros campos do saber, tais como a Sociologia, a Antropologia e a Psicologia, mas o que a identifica, em diferenciação a essas outras áreas, é que ela é um espaço de ação-intervenção direta no meio social. Em outros termos, a Educação constitui-se de um campo de saber cujo aspecto central é o agir intencional em uma realidade de caráter eminentemente social. Portanto, segundo esta mesma autora, "[...] a reflexão, o estudo e a investigação sobre seus modos de intervir é que constitui sua área privilegiada de construção do conhecimento" (GATTI, 2002, p. 62); fato sobre o qual os mestrandos parecem demonstrar, em suas falas, uma certa concordância com as ideias da autora.

Por esta razão é que, talvez, as explicações fornecidas pelos estudantes nos balanços do saber apontam quase sempre para o espaço educativo da escola, bem como para os atores e ações que lhe são peculiares. Na opinião dos sujeitos desta pesquisa, ser um pesquisador em Educação é ser um incansável "caçador" de respostas para as questões que afligem a vida de quem tem o ensino como uma missão a ser bem desempenhada: o professor. Mas, como isso pode e/ou deve ser feito? A resposta para esta questão necessita, sem dúvidas, de uma apreciação mais acurada, haja vista não ser tão simples a determinação de modos de agir na pesquisa em que a interação é tão fortemente marcada.

Adentrar um espaço de relações conflitivas e culturalmente marcadas como a escola, por exemplo, impõe ao pesquisador, até mesmo o mais experiente, atenção redobrada às nuances de significação que configuram esse espaço. $\mathrm{Na}$ esteira dessas considerações, vale salientar que os mestrandos, partícipes da pesquisa, parecem comungar do aspecto interventivo da pesquisa em Educação de que nos fala Gatti (2002).

Posso considerar [que para] um objeto de estudo [ser] bem construido deve estar situado no tempo e no espaço e deve suscitar dúvidas e ques- 
tionamentos que pedem respostas. O trabalho do pesquisador é tentar responder ou elucidar estas questões consciente de que sua pesquisa irá contribuir para a solução de problemas da Educação, senão ao menos ajudar a esclarecê-los. (Kássia/UFC).

A pesquisa, e principalmente você que é bolsista de estabelecimento público, você tem que ter aquela consciência que seu trabalho tem que servir para a sociedade, dar um retorno social, então, a pesquisa também é isso, retorno social, em especial para a escola. (João/UECE).

A pesquisa tem, para esses sujeitos, um caráter de intervenção na e sobre a realidade do fazer educacional. Essa compreensão realça o fato de que os mestrandos anseiam por uma educação de melhor qualidade e mais efetiva em seu caráter instrucional, convocando para a pesquisa, e/ou para o pesquisador, um pouco da responsabilidade de prover essa melhora. Contudo, pergunto-me se eles, paralelamente aos seus anseios em relação à pesquisa, compreendem que essa atividade e os resultados dela provenientes não têm o mesmo poder de uma política pública para intervir na realidade dos espaços educativos. Os resultados de seus estudos até podem (e devem) inspirar os administradores do serviço público a fomentar mudanças e, efetivamente, "contribuir para a solução de problemas da Educação", mas, talvez, pouco possam fazer para alterar os problemas agudos que foram percebidos por eles (estudantes) no cenário em que planejaram ambientar os seus trabalhos de pesquisa.

Devido ao anseio por mudanças na Educação, em especial àquela que se desenvolve no espaço escolar, os estudantes de mestrado, ao falarem mais especificamente sobre a construção do objeto de estudo, associam-no diretamente a um tema que deve ser abordado por um pesquisador da área. Geralmente são temas que representam os principais problemas enfrentados pelos atores sociais no campo educacional, com ênfase maior para o espaço escolar.

O que caracteriza uma pesquisa em Educação é o objeto de estudo, que deve estar voltado para o ensino, a aprendizagem, a formação do professor, a prática pedagógica, as condições de trabalho do professor, a escola, as metodologias de ensino, a avaliação, etc. (Alexandra/UFC).

A suscitação de possíveis temas de pesquisa elencados por Alexandra revela não apenas o seu entendimento segundo o qual a pesquisa em Educação deve 
ter como cenário a escola, mas e, sobretudo, demostra que os velhos fantasmas que assustam a escola brasileira ainda não foram vencidos. Assim, a mestranda vê que o ensino e suas metodologias, "[...] a aprendizagem, a formação do professor, a prática pedagógica, as condições de trabalho do professor, [...] a avaliação" não são problemas que devam circunscrever-se apenas ao universo escolar, mas devem também se espraiar para o ambiente acadêmico em forma de pesquisa. Com isso, eles reafirmam como característica principal da pesquisa na Educação o envolvimento "daquele que deseja conhecer" com a "realidade a ser conhecida", ainda que esta já lhe apresente alguma familiaridade.

Estou no primeiro semestre do Mestrado e estou cursando uma disciplina sobre pesquisa, com o intuito de conhecer e elaborar novos conceitos e melhorar o meu projeto de pesquisa. Mesmo com essas inquietações e com a necessidade de aprender cada vez mais sobre pesquisa, me considero um pesquisador, pois não me aquieto com a realidade. Um pesquisador deve ser um curioso, um militante, uma pessoa disposta a conhecer e mudar a realidade engessada pelo conformismo. (Josivaldo/UFC).

As minhas expectativas são de construir e produzir conhecimento que me possibilite dar algum retorno pra sociedade, da formação que eu tive aqui na Universidade pública, porque não é fácil chegar até aqui, pra mim não foi. Então, eu penso que eu devo isso à sociedade. Eu quero construir conhecimento e a minha expectativa é poder dar um retorno à sociedade desse conhecimento que eu venha a construir. Seja atuando como professora, na rede pública, ou trabalhando com a formação dos professores, isso é o que eu acredito que seja uma coisa fundamental pra educação de qualidade. (Mariana/UFC).

A intervenção de que nos falam os estudantes, no entanto, parece algumas vezes, como no caso explícito da fala de Josivaldo, ser acompanhada de um julgamento acerca dessa realidade. Para este estudante de mestrado, os problemas educacionais que ele observa, e que configuram uma realidade a qual chamou de "engessada", têm sua origem no conformismo de alguém. E quem seria este alguém? Seus colegas professores, submetidos, às vezes, as mais diversas condições de trabalho? Os gestores escolares, submetidos hierarquicamente às determinações de seus superiores administrativos? Enfim, para Josivaldo, os problemas observados em seu contexto de atuação parecem ser analisados menos por uma hipótese do que por uma avaliação direta. Essa constatação, portanto, 
pode levantar a suspeita de que muitos dos sujeitos que se iniciam na atividade de pesquisa em Educação tendem a abordar, de modo "valorativo" e "militante", os fenômenos da realidade em que atuam, notadamente aquela em que se processam ações de natureza instrucional, e que apresenta certa carência de uma reflexão e de uma ação mais aprofundada por parte dos indivíduos envolvidos, como, por exemplo, demonstra o desejo engajado de Mariana.

Assim sendo, observo que a pouca experiência ainda não lhe permite ver a necessidade de uma postura mais compreensiva, por meio da qual o pesquisador deve analisar e levar em consideração as condições e os contextos em que transcorrem os processos no interior das instituições, bem como as razões pelas quais eles se apresentam daquela maneira. Uma postura compreensiva, ou uma "leitura em positivo" da realidade, como diria Charlot (2000), pode ajudar o investigador a não exercer a pesquisa em Educação apenas como uma atividade de "militância cega" e de caráter unidirecional, na qual ele (o pesquisador) se tornará um exímio apontador dos "erros" cometidos pelos sujeitos pesquisados em seu espaço de atuação. A consequência de uma postura avaliativa em pesquisa é sempre uma leitura menos plural, menos dialógica e mais "reducionista" da realidade a ser estudada. Assim, ao término da pesquisa, a contribuição para o enfrentamento das dificuldades e dos desafios que nela foram identificados pode ser muito pequena ou, quiçá, até mesmo, nenhuma.

Não quero dizer com isso, entretanto, que o pesquisador, seja iniciante ou não, em seu trabalho, não possa realizar ou tecer nenhuma avaliação acerca daquilo que é seu foco de estudo, a fim de melhor apreendê-lo e/ou aperfeiçoá-lo. O que me preocupa é, pois, a condução desse processo, uma vez que, na pesquisa em Ciências Humanas, e igualmente no campo da Educação, o pesquisador tem primordialmente a função de conhecer uma realidade na qual também está presente o seu outro, e com o qual deve tentar estabelecer um diálogo não apenas simétrico, mas também justo, respeitoso e democrático. Afinal, compreendo que a avaliação é também, e antes de tudo, uma importante atividade de (re) conhecimento da nossa realidade.

Contudo, é extremamente relevante ter em mente que a presença do pesquisador em um lócus de investigação como a escola, já mencionada aqui como exemplo, tende a despertar algumas interpretações não muito agradáveis e/ou amigáveis por parte de quem atua nesse espaço. Como bem observa Charlot (2002), o relacionamento que se estabelece entre os professores da Educação Básica e os pesquisadores que frequentam as escolas

[...] é, muitas vezes, vivido pelos professores como situação de avaliação, numa relação hierárquica: o professor [...] [pesquisador] pertence à uni- 
versidade e a universidade despenca nas cabeças a hierarquia do saber. [...]; e qualquer que seja o comportamento do professor da universidade, por mais simpático que seja, o professor [da Educação Básica] vai sentir-se avaliado, vai sentir uma hierarquia intelectual. (CHARLOT, 2002, p. 92).

Com efeito, isto se deve ao fato de que, nesse encontro, "seus mundos" passam a se estabelecerem como contextos diferenciados, mesmo que o pesquisador tenha, em alguma medida, uma relação próxima com a escola. Em sendo esta a situação, assim como em qualquer outra situação investigativa, o fazer da pesquisa exigirá impreterivelmente do pesquisador que este mantenha, no diálogo com os demais atores, um posicionamento exotópico, a fim de que possa analisar, com um certo estranhamento, as relações e os significados construídos naquele espaço que lhe é tão familiar. A expressão posicionamento exotópico, portanto, está relacionada à necessidade de o pesquisador não sobrepor sua posição externa ao mundo dos pesquisados.

Tal preocupação é relevante, segundo Amorim (2001), para que, durante a análise, não se torne impossível a compreensão do pesquisador em relação ao discurso do sujeito pesquisado, visto que, sendo ambos produtores de textos, o texto do segundo pode ser emudecido em função do texto do primeiro. Desse modo, o distanciamento na pesquisa qualitativa é necessário e se chama exotopia, termo que designa uma posição espacial e também temporal do pesquisador em relação ao contexto e ao texto dos pesquisados. Sendo este o entendimento, penso que precisamos estar atentos ao fato de que, para além dos aspectos que envolvem os outros sujeitos da pesquisa, conforme discutido acima, em alguns casos, e em especial quando o pesquisador iniciante decide estudar a sua própria realidade de trabalho, a exemplo da escola onde atua, o distanciamento exotópico também deverá ocorrer em relação a si mesmo e às suas funções na escola.

Esta é, sem dúvidas, uma tarefa bastante complexa e que o investigador iniciante terá de gerenciar, paralelamente aos desafios do curso de mestrado, já aludidos no início deste texto.

Eu descobri que fazendo pesquisa com as [nossas] turmas de trabalho, podemos melhorar a nossa prática, não sendo, muitas vezes, obrigado a fazer pesquisas grandiosas. (Rosa/UECE).

Apesar dos riscos inerentes à proximidade com a realidade estudada, o fazer da pesquisa no campo da Educação tende a ser mais característico para 
quem está começando quando o pesquisador atua diretamente sobre suas práticas profissionais. Trata-se, pois, de um entendimento bastante interessante na medida em que a pesquisa sobre problemas educacionais deve verdadeiramente contribuir para a melhoria desses problemas. Nesse sentido, interrogar-se a si mesmo antes de interrogar o campo em que atua parece ser uma percepção rica, um saber fundamental, construído pelos mestrandos em Educação, pois demonstra a compreensão de que, aliada à atividade de pesquisa, a postura investigativa deve ter um olhar atento voltado para os problemas que, como professores, enfrentam no exercício cotidiano da docência.

Em outras palavras, a escola não pode ser apenas fonte de dados que sirvam unicamente para a escrita de teses e dissertações em educação, mas deve ser um ambiente que possa crescer e melhorar a partir do que esses dados podem elucidar.

Me considero uma pesquisadora em Educação por tentar contribuir com o ensino-aprendizagem de crianças que estão se alfabetizando, visando um retorno tanto da minha experiência como professora quanto de pesquisadora para as práticas de sala de aula. (Judithe/UFC).

Essa maneira de compreender a pesquisa encontra fulcro também nas considerações de Demo (2010), para quem a pesquisa no âmbito da Educação pode produzir conhecimento politicamente engajado e configurar-se como uma prática de extrema importância para a docência e para a própria aprendizagem do ser professor, em particular a aprendizagem da autoria, uma vez que é esta que o define como professor, muito mais que os títulos que possui ou a atividade de ensino. Em função disso, o autor tem defendido a relevância de o professor ser também um pesquisador de sua prática, o que, de modo bastante evidente, também se apresenta nas falas de Rosa e Judithe, acima. As mestrandas, portanto, mostram-se inseridas nessa perspectiva: a de interrogar seu próprio campo e de tentar gerar conhecimento acadêmico a partir do exercício de olhar para sua própria prática.

Contudo, antes de se pensar nas possíveis soluções para os problemas da realidade educacional, defendo que é preciso compreender a fenomenologia que circunda tais problemas, afastando-se das ideias meramente utilitaristas em relação ao saber-fazer-pesquisa. Além disso, se acrescentarmos as dificuldades que dizem respeito principalmente a alguns entraves proporcionados pelos sistemas de ensino à complexidade de o pesquisador iniciante ser sujeito de sua própria investigação, teremos outros elementos a serem discutidos mais 
aprofundadamente em outro momento. Um desses entraves, apenas a título de exemplificação, tem a ver com a sobrecarga de trabalho e as condições desfavoráveis em que atuam os professores nas escolas brasileiras, as quais parecem estimular a formulação de algumas resistências e ideias em relação ao trabalho dos pesquisadores, conforme tem nos alertado Charlot (2002).

Acrescido a isto, o pouco tempo para planejar as aulas e para se dedicar à leitura sobre os conteúdos que lecionam pode ser outro fator determinante no que concerne ao sentimento que os professores da Educação Básica desenvolvem durante as visitas que recebem de professores pesquisadores. É provável que aqueles se sintam negativamente avaliados por estes e que temam testemunhar as suas fragilidades expostas e divulgadas em inúmeros relatórios de pesquisa. A combinação desses fatores com a inexperiência do pesquisador iniciante, caso não tenha uma orientação segura e eficaz, pode gerar, por sua vez, situações no mínimo desagradáveis para ambos os sujeitos do processo e, sem dúvidas, bastante infrutíferas aos resultados da pesquisa, a exemplo do falseamento de dados e da formulação equivocada de instrumentos de geração desses dados.

Para tornar mais clara essa ideia do falseamento dos dados, quando falo sobre a inexperiência do pesquisador, estou me referindo ao fato de que ele pode tentar, via "autoridade" dos gestores, obter "forçosamente" a colaboração dos professores. Essa colaboração seria, indubitavelmente, mais frutífera e proveitosa aos objetivos da pesquisa se fosse conquistada, ao invés de "imposta" pelas hierarquias administrativas. Conforme nos explica Freitas (2003, p. 37), "[...] embora pesquisadores e pesquisados ocupem lugares diferentes, a pesquisa deve sempre se constituir como um encontro entre sujeitos". Nesse sentido, para finalizar essa reflexão, argumento em favor de que um dos maiores aprendizados para o pesquisador iniciante, nessa situação, é o de compreender, ainda que às custas de alguns tropeços e contratempos, que a pesquisa é uma atividade a ser construída sempre entre "iguais".

\section{Considerações finais}

Nos 30 balanços que foram analisados, pude perceber que os mestrandos possuem uma compreensão sobre o que é fazer pesquisa nascida de suas experiências no próprio campo da Educação. Para eles, essa atividade implica necessariamente uma descoberta de respostas com vistas a uma solução de problemas, os quais precisam estar diretamente envolvidos com a prática de quem investiga. Nesse sentido, a pesquisa é concebida como uma atividade 
comprometida socialmente e engajada politicamente. Para além desses aspectos macrossociais da pesquisa, ela não pode prescindir, segundo os mestrandos, de uma dimensão técnica bastante acentuada e deve assumir características que são "impostas" pela prática da comunidade acadêmica.

Para eles, no campo da Educação, a investigação se caracteriza fundamentalmente por enfocar a prática docente, seus conflitos e dificuldades. A ação didático-pedagógica seria o cerne do olhar do pesquisador, uma vez que esta tende a lhes provocar desafios em busca de ações transformadoras e de melhorias para o trabalho do professor. Nesse sentido, é possível inferir que os temas mais recorrentes, e, portanto, de maior interesse para os pesquisadores iniciantes no campo da Educação, sejam aqueles que associam a prática docente com as dificuldades de aprendizagem por parte dos alunos.

Sobre este percurso de apreensão da realidade educacional, chamo a atenção para o fato de que, na trajetória dos estudantes recém-ingressos na Pós-Graduação em Educação stricto sensu, não será difícil que eles se deparem com um deficitário e negligente processo de democratização nos sistemas de ensino, bem como com as resistências que lhes serão proporcionadas pelos atores que movimentam esses sistemas. Por isso, uma orientação segura e eficaz se faz necessária no que diz respeito aos procedimentos metodológicos e analíticos no lócus do estudo e à perspectiva de pesquisa a ser adotada pelos aprendizes da investigação acadêmica, a fim de que possam se apropriar satisfatoriamente dessa nova e instigante atividade.

Com efeito, uma incursão inicial pelos dados que construímos a partir dos balanços do saber nos permitiu vislumbrar aspectos importantes sobre a relação que os mestrandos constroem com a atividade de pesquisa. Contudo, a discussão sobre esses aspectos, assim como sobre muitos outros, que aqui não foram sequer apontados, precisa ser mais aprofundada. Um exemplo desses aspectos diz respeito às características que dão contorno aos saberes e às relações com o saber desses sujeitos no campo da pesquisa educacional, bem como o sentido que eles atribuem às opções teóricas e metodológicas que adotam em seus estudos. Como disse na introdução deste texto, propus uma conversa, um bate-papo com o leitor e, pelo visto, parece que apenas começamos.

\section{REFERÊNCIAS}

AMORIM, M. O pesquisador e seu outro: Bakhtin nas Ciências Humanas. São Paulo: Musa Editora, 2001. 
AMORIM, M. A contribuição de Mikhail Bakhtin: a tripla articulação ética, estética e epistemológica. In: FREITAS, M. T.; JOBIM E SOUSA, S.; KRAMER, S. (Orgs.). Ciências Humanas e Pesquisa: leituras de Mikhail Bakhtin. São Paulo: Cortez, 2003. p. 11-25.

BOURDIEU, P. Razões práticas: sobre a teoria da ação. São Paulo: Papirus, 1996.

BOURDIEU, P. O poder simbólico. Rio de Janeiro: Bertrand Brasil, 1998.

BRUNER, J. Uma nova teoria de aprendizagem. Rio de Janeiro: Bloch, 1966.

CHARLOT, B. Da relação com o saber: elementos para uma teoria. Porto Alegre: Artmed, 2000 .

CHARLOT, B. Formação de professores: a pesquisa e a política educacional. In: PIMENTA, S. G.; GHEDIN, E. (Orgs.). Professor reflexivo no Brasil: gênese e crítica de um conceito. São Paulo: Cortez, 2002. p. 89-108.

DEMO, P. O educador e a prática da pesquisa. Ribeirão Preto: Editora Alphabeto, 2010.

DIEB, M. A atividade de pesquisa em ciências humanas e a ludicidade: o que as brincadeiras podem comunicar? In: COSTA, M. F. V.; COLAÇO, V. F. R.; COSTA, N. B. (Org.). Modos de brincar, lembrar e dizer: discursividade e subjetivação. Fortaleza: Edições UFC, 2007. v. 48, p. 157-174.

FREITAS, M. T. A perspectiva sócio-histórica: uma visão humana da construção do conhecimento. In: FREITAS, M. T.; JOBIM E SOUSA, S.; KRAMER, S. (Orgs.). Ciências Humanas e Pesquisa: leituras de Mikhail Bakhtin. São Paulo: Cortez, 2003. p. 26-38.

GATTI, B. A. A construção da pesquisa em Educação no Brasil. Brasília: Plano Editora, 2002.

GUARESCHI, P. Ética. In: STREY, M. N. et al. (Org.). Psicologia Social contemporânea: livro-texto. 5. ed. Petrópolis: Vozes, 2001. p. 49-57.

GUARESCHI, P. Alteridade e relação: uma perspectiva crítica. In: ARRUDA, Â. (Org.). Representando a alteridade. 2. ed. Petrópolis: Vozes, 2002. p. 149-161.

Texto recebido em 26 de novembro de 2015.

Texto aprovado em 28 de janeiro de 2016. 
